\title{
Five new species of the land snail genus Landouria Godwin-Austen, 1918 (Gastropoda, Camaenidae) from northeastern Thailand, with note on genitalia and radula morphology of Landouria diplogramma (Möllendorff, 1902)
}

\author{
Benchawan NAHOK ${ }^{1}$, Sakboworn TUMPEESUWAN ${ }^{2} \&$ \\ Chanidaporn TUMPEESUWAN ${ }^{\circledR 3, *}$ \\ 1,2,3 Department of Biology, Faculty of Science, Mahasarakham University, \\ Kantharawichai District, Maha Sarakham, 44150 Thailand. \\ ${ }^{1}$ Present address: Educational Research Development and Demonstration Institute, \\ Srinakharinwirot University, Ongkharak District, Nakhon Nayok, 26120 Thailand. \\ ${ }^{2}$ Palaeontological Research and Education Centre, Mahasarakham University, \\ Kantharawichai District, Maha Sarakham, 44150 Thailand. \\ *Corresponding author: ctumpeesuwan@yahoo.com \\ ${ }^{1}$ Email: nahok.b@gmail.com \\ 2Email: stumpeesuwan@yahoo.com \\ ${ }^{1}$ urn:1sid:zoobank.org:author:C9810F4C-B656-4C61-8CD1-5CEA27D04A28 \\ ${ }^{2}$ urn:Isid:zoobank.org:author:F7533397-1513-4A6C-880D-27599946A227 \\ ${ }^{3}$ urn:Isid:zoobank.org:author:0F4F4307-1677-4E51-8C83-B87CF3809AED
}

\begin{abstract}
Five new species of the terrestrial snail genus Landouria Godwin-Austen, 1918 (Camaenidae) are described from northeastern Thailand, based on shell features, radular morphology, genital anatomy, and DNA sequence data: Landouria circinata sp. nov., L. tuberculata sp. nov., L. trochomorphoides sp. nov., L. chloritoides sp. nov., and $L$. elegans $\mathrm{sp}$. nov. These species are phylogenetically well separated from each other by mtDNA phylogeny and COI sequence divergences of 0.073-0.156. The record of Thaitropis Schileyko, 2004 (currently synonymized with Landouria) in Thailand is re-interpreted as referring to L. diplogramma (Möllendorff, 1902) comb. nov.
\end{abstract}

Keywords. Camaenidae, Landouria, Thailand, systematics, phylogeny.

Nahok B., Tumpeesuwan S. \& Tumpeesuwan C. 2021. Five new species of the land snail genus Landouria Godwin-Austen, 1918 (Gastropoda, Camaenidae) from northeastern Thailand, with note on genitalia and radula morphology of Landouria diplogramma (Möllendorff, 1902). European Journal of Taxonomy 767: 142-166. https://doi.org/10.5852/ejt.2021.767.1495

\section{Introduction}

The genus Landouria Godwin-Austen, 1918 was introduced for Helix huttoni L. Pfeiffer, 1842, its type species from the Himalayas of northern India, and four additional species, viz. L. aborensis Godwin- 
Austen, 1918 from Abor Hill (Nepal), L. damsangensis Godwin-Austen, 1918 from Damsang in Sikhim (India), L. hengdanensis Godwin-Austen, 1918 from Hengdan Peak on Burrai Rang (near the frontier of Myanmar and India), and L. radleyi (Jousseaume, 1894) from Harputtalle in Ceylon (Sri Lanka). As such, species of Landouria are characterized by (1) small depressed shell with umbilicus broad and open, and last whorl descending in front, (2) lack of dart apparatus and mucous glands in the genital system, (3) gametolytic sac present on vagina, and (4) fragellum present. Recently, many additional species have been described, so that currently more than 40 nominal species are known (e.g., Hirano et al. 2014; Dharma 2015; Köhler et al. 2018; Nurinsiyah et al. 2019; Tumpeesuwan \& Tumpeesuwan 2019; Páll-Gergely et al. 2020). However, 19 of these nominal species were synonymized by Richardson (1985) (see Tumpeesuwan \& Tumpeesuwan 2019: table 1), five of which were subsequently resurrected as accepted species by Nurinsiyah et al. (2019), thus illustrating the complexity of the taxonomy of the genus Landouria.

In the present study, we describe five new species of Landouria from northeastern Thailand based on their shell morphology, genital anatomy, radular structure, and a phylogenetic analysis of mtDNA sequence data.

\section{Material and methods}

Empty shells and living specimens were collected from limestone and sandstone hills in northeastern Thailand. Three living adult specimens of each species were drowned in water for 24 hours. Foot muscle tissue of each specimen was cut and preserved in $80 \%$ ethanol, and keep in a freezer at $-20^{\circ} \mathrm{C}$. The remaining parts were preserved in $70 \%$ ethanol for anatomical study.

\section{Morphological studies}

A digital vernier calipers was used to take the following shell measurements (Table 1): shell height (SH), shell width (SW), aperture height (AH), aperture width (AW), and umbilicus width (UW). The number of whorls of adult shells was counted by drawing straight lines to separate the whorls and then the whorls were counted as indicated in Fig. 1. Adult snails were dissected to examine their genitalia under a stereo microscope. Radulae were extracted from the buccal mass and examined under a scanning electron microscope, following the methods of Geiger et al. (2007). The material studied is deposited in the land snail collection of the Natural History Museum, Mahasarakham University (NHMSU-00023 to 00034).
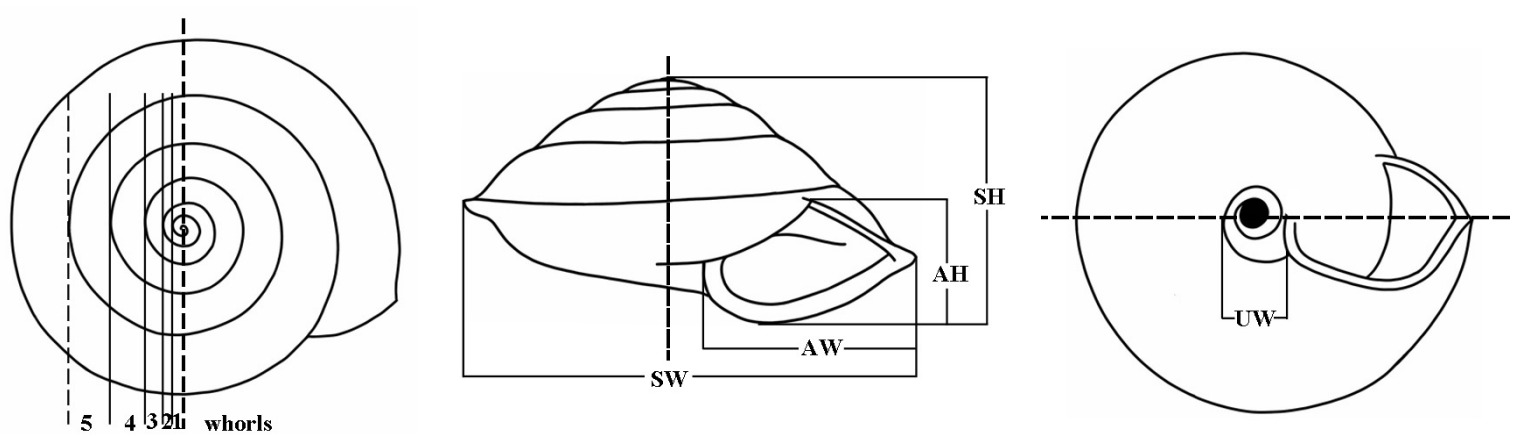

Fig. 1. Schematic drawings of shell indicating how the number of whorls was counted and how the measurements were taken. Abbreviations: $\mathrm{AH}=$ aperture height; $\mathrm{AW}=$ aperture width; $\mathrm{SH}=$ shell height; SW = shell width; UW = umbilicus width. 


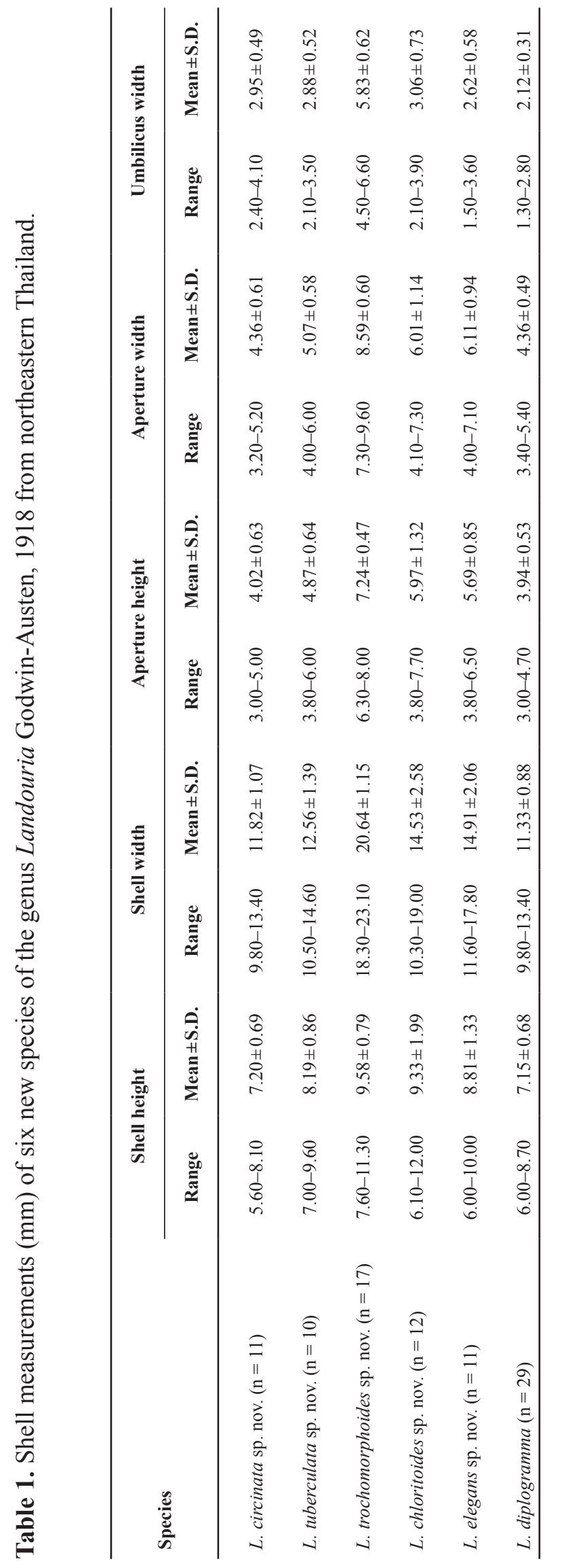




\section{DNA sequence analyses}

DNA was extracted from foot muscle tissue using the GF-1 Nucleic Acid Extraction Kit (Vivantis Technologies Sdn. Bhd, Malaysia) following the manufacturer's protocol. Fragments of the cytochrome c oxidase subunit 1 (COI) and mitochondrial 16S rRNA (16S) genes were used to construct a phylogenetic tree of species of Landouria. COI was also used to evaluate genetic divergences (p-distance) between species. The fragments of COI and 16S were amplified by PCR using the primer pairs L1490 and H2198 (Folmer et al. 1994), and 16Scs1 (Chiba 1999) and 16S_MN3R (Neiber et al. 2017) respectively. Reaction conditions were as follows: an initial denaturation step at $94^{\circ} \mathrm{C}$ for $2 \mathrm{~min} ; 36$ cycles of $94^{\circ} \mathrm{C}$ for $30 \mathrm{~s}, 50^{\circ} \mathrm{C}$ for $45 \mathrm{~s}$ and $72^{\circ} \mathrm{C}$ for $45 \mathrm{~s}$; and a final extension step at $72^{\circ} \mathrm{C}$ for $5 \mathrm{~min}$ for COI, and an initial denaturation step at $94^{\circ} \mathrm{C}$ for $2 \mathrm{~min} ; 36$ cycles of $94^{\circ} \mathrm{C}$ for $30 \mathrm{~s}, 50^{\circ} \mathrm{C}$ for $30 \mathrm{~s}$ and $72^{\circ} \mathrm{C}$ for $30 \mathrm{~s}$; and a final extension step at $72^{\circ} \mathrm{C}$ for 5 min for $16 \mathrm{~S}$. The PCR products were checked with $1 \%$ agarose gel electrophoresis. Successful PCR products were sent for NGS-based sequencing at Celamics DNA Sequencing Services (Seoul, Korea) and $1{ }^{\text {st }}$ BASE DNA Sequencing Services (Selangor, Malaysia).

\section{Phylogenetic analysis}

The quality of the mtDNA sequences was checked manually with Bioedit ver. 7.0.9 (Hall 1999, 2001). Sequences were aligned using the Clustal W algorithm in MEGA X (Kumar et al. 2018). New sequences were deposited in GenBank under the accession numbers MN449400-MN449404, MN449408 and MN449411 for COI, and MZ435745-MZ435749, MZ435751 and MZ435752 for 16S. We included sequences of Landouria from Timor-Leste, China, and Sumatra, Indonesia (Köhler et al. 2018) in our analyses, and used sequences from Euhadra peliomphala (Pfeiffer, 1850) as outgroup following Hirano et al. (2014) and Nurinsiyah et al. (2019) (Table 2).

The program jModelTest ver. 2.1.10 (Posada 2008; Darriba et al. 2012) was used to determine the best fitting model of DNA substitution using the Akaike Information Criterion (AIC) (Akaike 1974). Sequence divergences were calculated with pairwise p-distances in MEGA X. Phylogenetic trees were constructed using neighbor-joining (NJ), maximum likelihood (ML) and Bayesian inference (BI).

The NJ tree was estimated in MEGA X and node support was calculated using the bootstrapping with 1000 replicates. The ML analysis was conducted with RAxML ver. 8.0.0 (Stamatakis 2014) applying the GTR $+F 0+G$ substitution model and 1000 bootstrap replicates to assess branch support. The concatenated sequence alignment was partitioned by gene, allowing different evolution rates for COI and 16S rRNA. The BI analysis was performed in MrBayes ver. 3.2.6 (Ronquist et al. 2012) and run for 2 million generations, with a sampling frequency of 100 generations. The first 2000 generations of each run were discarded as burn-in, the final consensus tree was built using the last 8002 trees. Convergence was confirmed by verifying that the standard deviations of split frequencies were below 0.01 . Support for nodes was defined as posterior probabilities. Finally, a 50\% majority-rule consensus tree with posterior probabilities as node support was constructed. Phylogenetic trees were displayed and edited using FigTree ver. 1.4.0 (Rambaut 2012).

Following Hirano et al. (2014), nodal support values were considered to be meaningful if $\geq 70 \%$ for bootstrapping or $\geq 0.95$ for posterior probabilities.

$$
\begin{aligned}
& \text { Abbreviations used for the genital parts } \\
& \begin{array}{ll}
\mathrm{ag} & =\text { albumen gland } \\
\mathrm{at} & =\text { atrium } \\
\mathrm{ep} 1 & =\text { proximal part of epiphallus } \\
\mathrm{ep} 2 & =\text { distal part of epiphallus } \\
\mathrm{fl} & =\text { flagellum }
\end{array}
\end{aligned}
$$




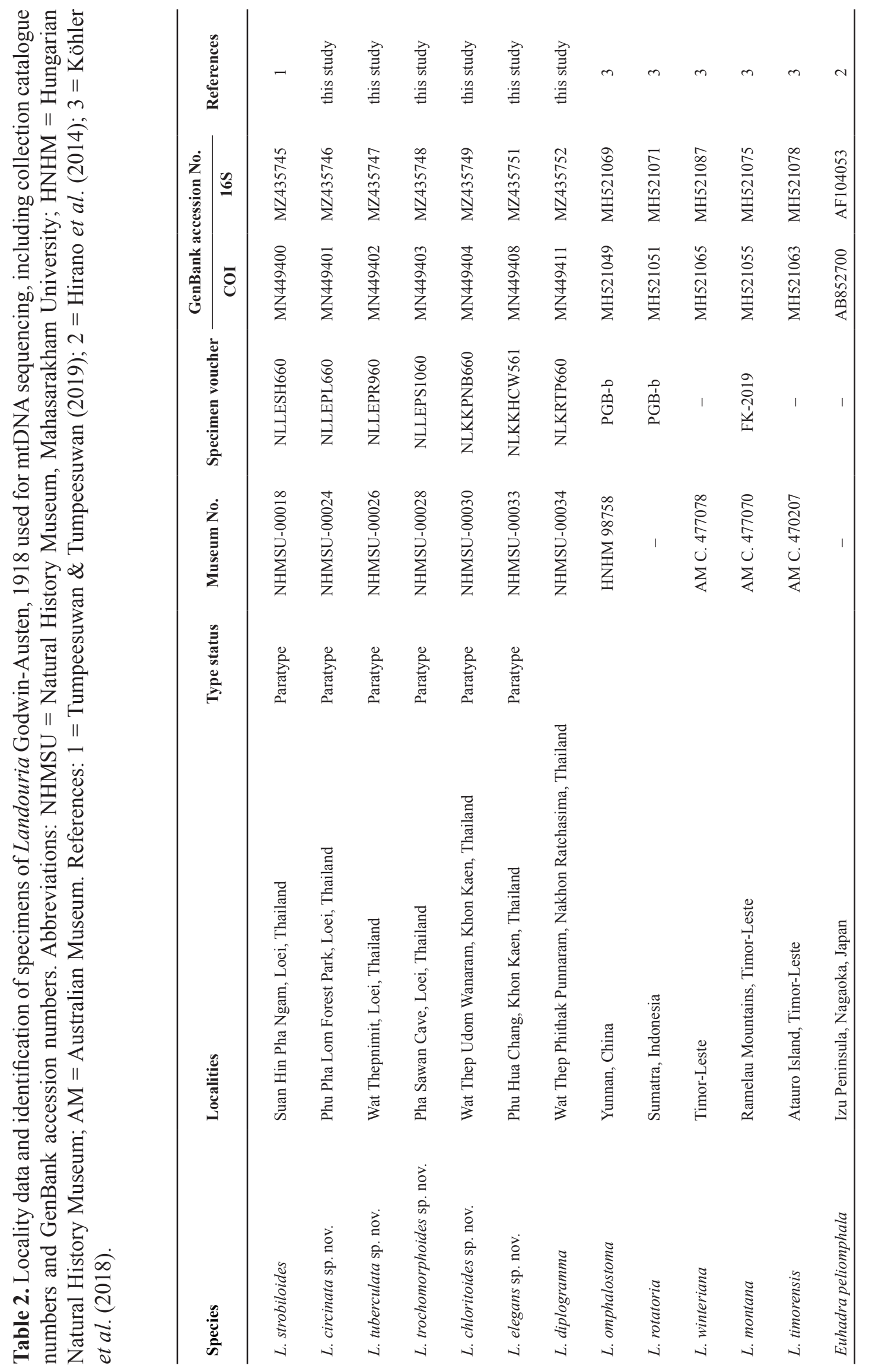




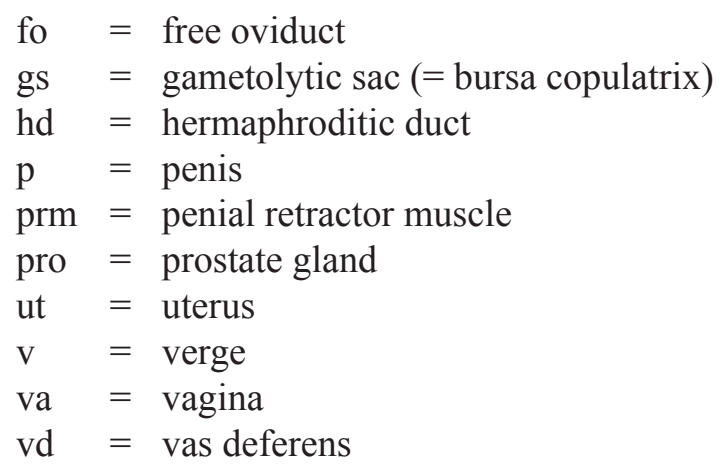

\section{Results}

\section{Molecular phylogeny}

The COI dataset included $655 \mathrm{bp}$, while the 16S rRNA dataset included $460 \mathrm{bp}$. The concatenated dataset therefore comprised $1115 \mathrm{bp}$.

The COI uncorrected p-distances within Thai species of Landouria ranged from 0.073 to 0.249 , whereas interspecific distances among species from Thailand, Timor-Leste, China, and Sumatra, Indonesia ranged from 0.073 to 0.249 (Table 3). The BI, ML and NJ phylogenetic trees reconstructed by combined analyses of the partial COI and 16S rRNA were congruent (Fig. 2).

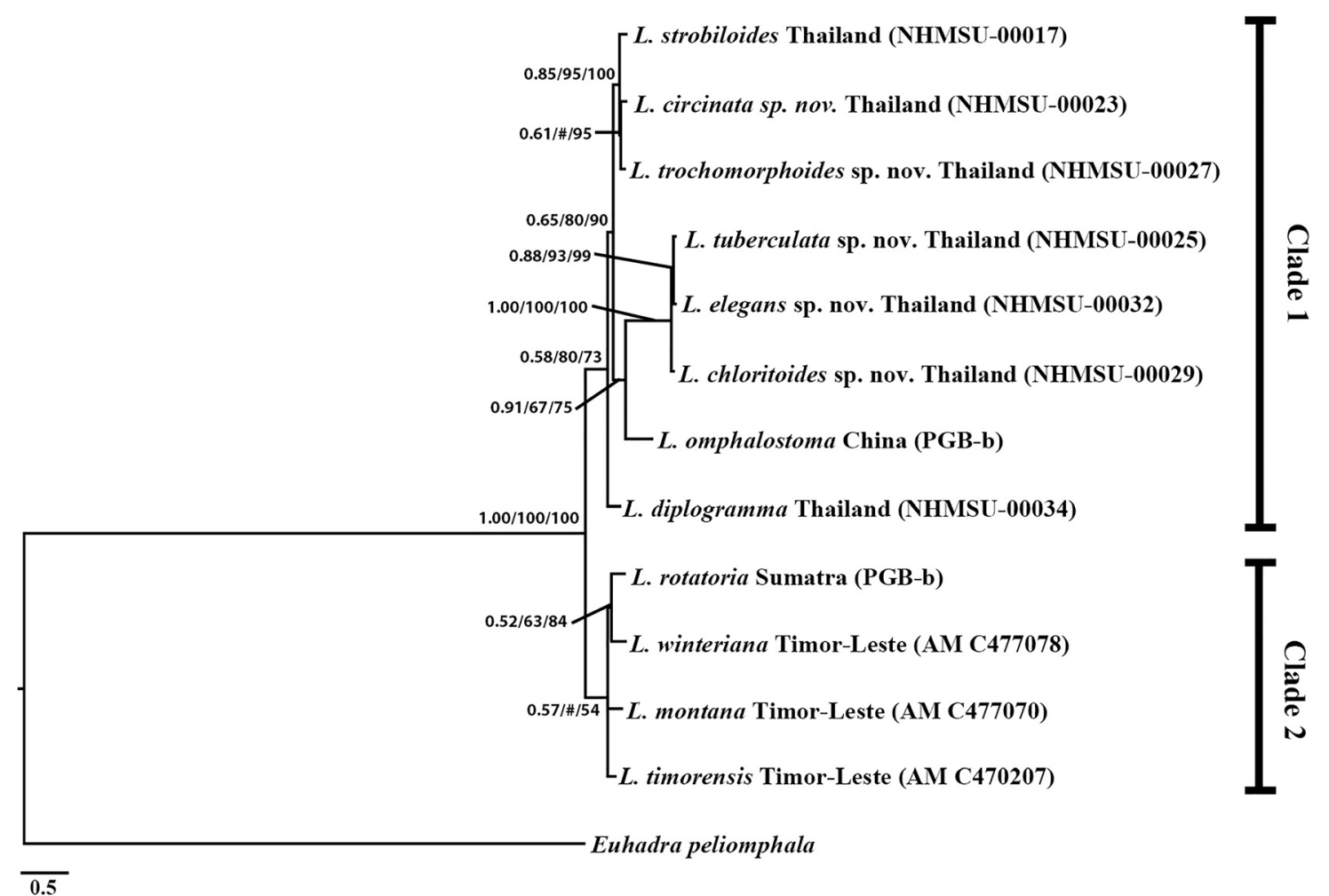

Fig. 2. Bayesian majority-rule consensus tree summarizing the phylogenetic relationships of species of Landouria Godwin-Austen, 1918 based on concatenated COI and 16S sequences. Numbers at nodes indicate branch support based on posterior probability (BI)/ bootstrapping (ML)/bootstrapping (NJ). \# indicates branches that received $<50 \% \mathrm{ML}$, NJ bootstrap support. Scale bar $=0.5$ substitutions $/$ site. 


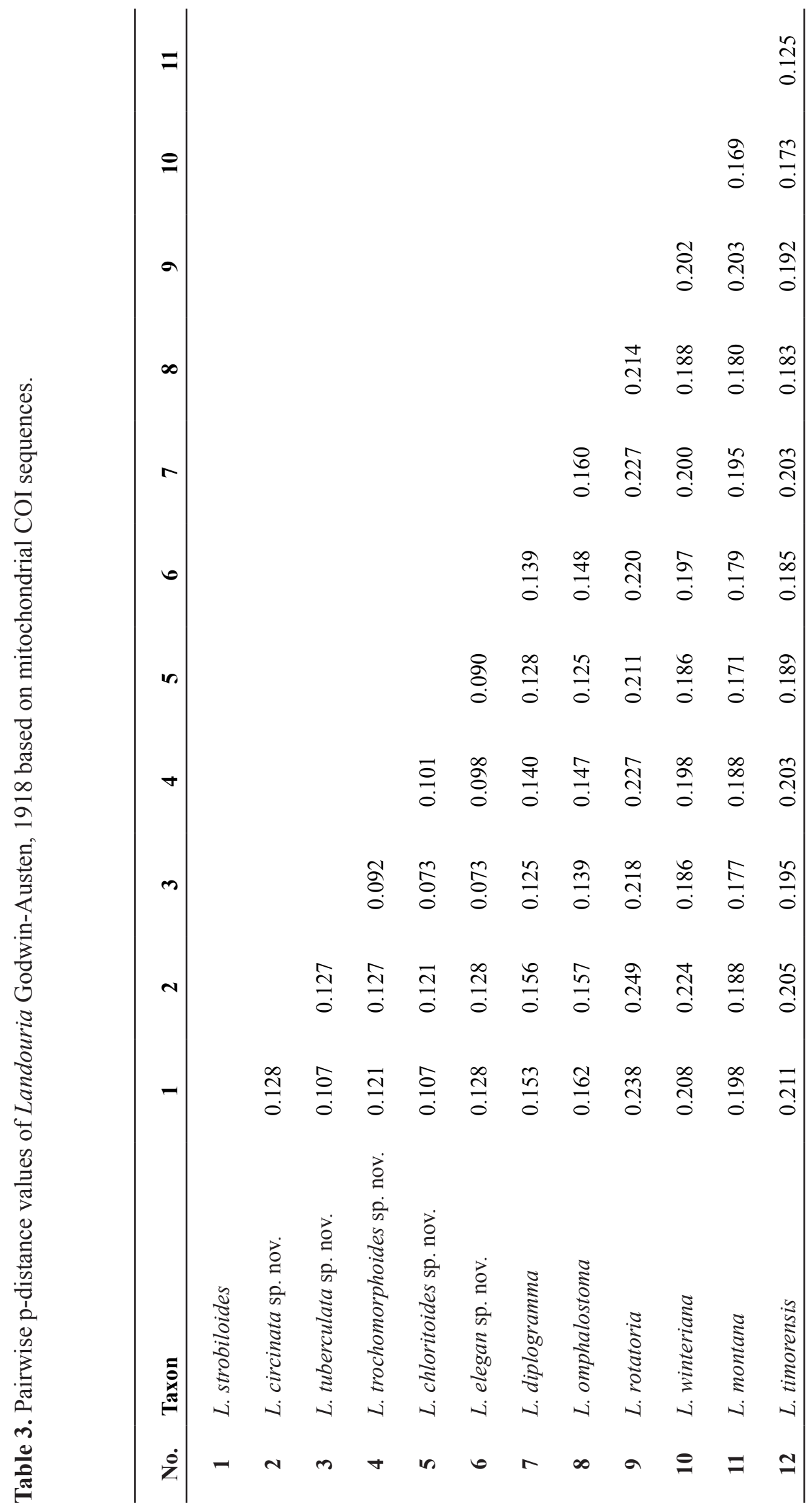


NAHOK B. et al., The genus Landouria from northeastern Thailand

The phylogenetic trees divided Landouria into two major clades which were strongly supported by a BI posterior probability of 1.00, and 100\% for ML and NJ bootstrapping (Fig. 2). These clades were the Mainland Southeast Asia clade and the Archipelago clade. The Mainland Southeast Asia clade contains Chinese and Thai taxa (8 species), while the Archipelago clade contains Timor-Leste and Sumatran taxa (4 species). The 8 species of Landouria from the Mainland Southeast Asia clade (i.e., L. strobiloides C. Tumpeesuwan \& S. Tumpeesuwan, 2019, L. circinata sp. nov., L. tuberculata sp. nov., L. trochomorphoides sp. nov., L. chloritoides sp. nov., L. elegans sp. nov., L. diplogramma (Möllendorff, 1902), and L. omphalostoma) were the sister group of the Archipelago clade with L. rotatoria (L. Pfeiffer, 1842), L. winteriana (L. Pfeiffer, 1842), L. montana Köhler, Shea \& Kessner, 2019, and L. timorensis Köhler, Shea \& Kessner, 2019 (Fig. 2).

\section{Systematics}

Class Gastropoda Cuvier, 1797

Order Stylommatophora A. Schmidt, 1855

Superfamily Helicoidea Rafinesque, 1815

Family Camaenidae Pilsbry, 1895

Genus Landouria Godwin-Austen, 1918

\section{Type species}

Helix huttonii L. Pfeiffer, 1842 (new name for Helix orbicula Hutton \& Benson, 1838), by original designation.

\section{Type locality}

Himalaya near Simla, Mahasu, northern India (Hutton \& Benson 1838).

\section{Distribution}

The genus is also reported from northeast India, west Himalaya, Nepal, Mandalay and Shan in Myanmar (Burma), Yunnan in China (Zilch 1966; Schileyko \& Kuznetsov 1998; Ramakrishna et al. 2010; Budha et al. 2015).

Schileyko \& Kuznetsov (1998) tentatively argued that Landouria is restricted to northern India, Nepal, northern Myanmar, and Sri Lanka. Yet, recently, species of Landouria have been reported from China (Páll-Gergely et al. 2013), Laos (Hirano et al. 2014), Timor-Leste (Köhler et al. 2018), Java in Indonesia (Nurinsiyah et al. 2019), and Thailand (Tumpeesuwan \& Tumpeesuwan 2019).

Landouria circinata sp. nov.

urn:lsid:zoobank.org:act:B434E62B-9FA6-43FB-B27F-A4B1B0413225

Figs 3A, 4A, 5A, 6A-C; Tables 1-4

Landouria sp. - Tanmuangpak et al. 2012: 7, 12, fig. 5y. - Tanmuangpak 2016: 125-126, figs 4.744.75 .

Landouria sp.4 - Ounchareon 2015: 40-42, figs 4.12, 4.13, 5.1, 5.7.

Landouria sp.2 - Yingkhamhang 2016: 21-22, 39-41, 43-45, 47-48, figs 4.3-4.4, 4.21b, 4.22c, 4.23b, $5.1 \mathrm{~b}, 5.2 \mathrm{~b}$. 


\section{Diagnosis}

Shell brownish-corneous, periphery angular, sharply keeled. Flagellum circinate; penis cylindrical and longer than vagina; base of gametolytic sac thick and stout. Radula with unicuspid short tongue-shaped central teeth.

\section{Etymology}

The Latin word 'circinata' refers to the coiled or curled flagellum which resembles the circinate vernation of a fern shoot.

\section{Type material}

\section{Holotype}

THAILAND • shell $(\mathrm{SH}=8.2 \mathrm{~mm}, \mathrm{SW}=13.8 \mathrm{~mm}, \mathrm{AH}=5.1 \mathrm{~mm}, \mathrm{AW}=5.1 \mathrm{~mm}, \mathrm{UW}=3.8 \mathrm{~mm})$; Loei Province, Mueang District, Phu Pha Lom Forest Park; 17³3'18.03" N, 10152'6.71" E; alt. 415 m; 7 Jun. 2017; B. Nahok and U. Chanlabut leg.; NHMSU-00023. (Fig. 3A)

\section{Paratypes}

THAILAND • 11 shells, 43 living specs; same collection data as for holotype; GenBank No. MN449401 and MZ435746; NHMSU-00024.

\section{Description}

Shell (Fig. 3A, Table 1). Dextral, medium sized, conical-lenticular, with six slightly convex whorls. Suture shallow. Apex obtuse, depressed and low-conical. Light brown at 4 early whorls, dark brown at 2 last whorls. Sharply keeled, with pale brown band on the peripheral keel. Umbilicus very deep and wide. Aperture lip somewhat thickened, rounded rhombic.

Genital system $(\mathrm{n}=3$ ) (Fig. 5A, Table 4). Penis very long, cylindrical, and curled, divided into two portions of equal length, internally with parallel, transverse folds, containing a short, rather rounded verge. Epiphallus short cylindrical, thinner than the penis. Flagellum slightly crenated and curled up, resembling the circinate vernation of a fern shoot, with thin grooves internally and tubercles on its surface at the end, internally with transverse robust folds. Vas deferens is a slender, cylindrical tube, thicker at the end where it connects to free oviduct; entering flagellum basally. Vagina less than half as long as penis, internally with four thin longitudinal pilasters. Free oviduct shorter than vagina. Gametolytic sac thickened at base, stout and gradually tapering distally to form a slender distal tube ending in a balloonshaped, medium-sized sac. Prostate gland very long, uterus long and swollen.

RAdUla $(n=3)$. Comprises 95 transverse rows with 57-61 teeth per row; radular formula: $(20)-(8-10)$ 1-(8-10)-(20). Central tooth symmetric, unicuspid, tongue-shaped; lateral teeth longer than central tooth and oblique, unicuspid, tongue-shaped (Fig. 6A). Marginal teeth tricuspid with medium-sized endocone; mesocone rather large, with rounded cusp; ectocone triangular (Fig. 6B-C).

\section{Remarks}

Landouria circinata sp. nov. resembles L. strobiloides (see Tumpeesuwan \& Tumpeesuwan 2019: fig. 3) in shell morphology, L. circinata sp. nov. has a smaller shell, a shallower suture, and darker peripheral zone than L. strobiloides (Table 4, Fig. 3A). Its central and lateral radular teeth are unicuspid and tongueshaped, whereas they are lanceolate in L. strobiloides (Table 4, Fig. 6A). The unique characters of L. circinata sp. nov. are its circinate flagellum and its penis that is much longer than the vagina (Fig. 5A), whereas $L$. strobiloides has a strobilus-like flagellum and a penis that is shorter than the vagina. 


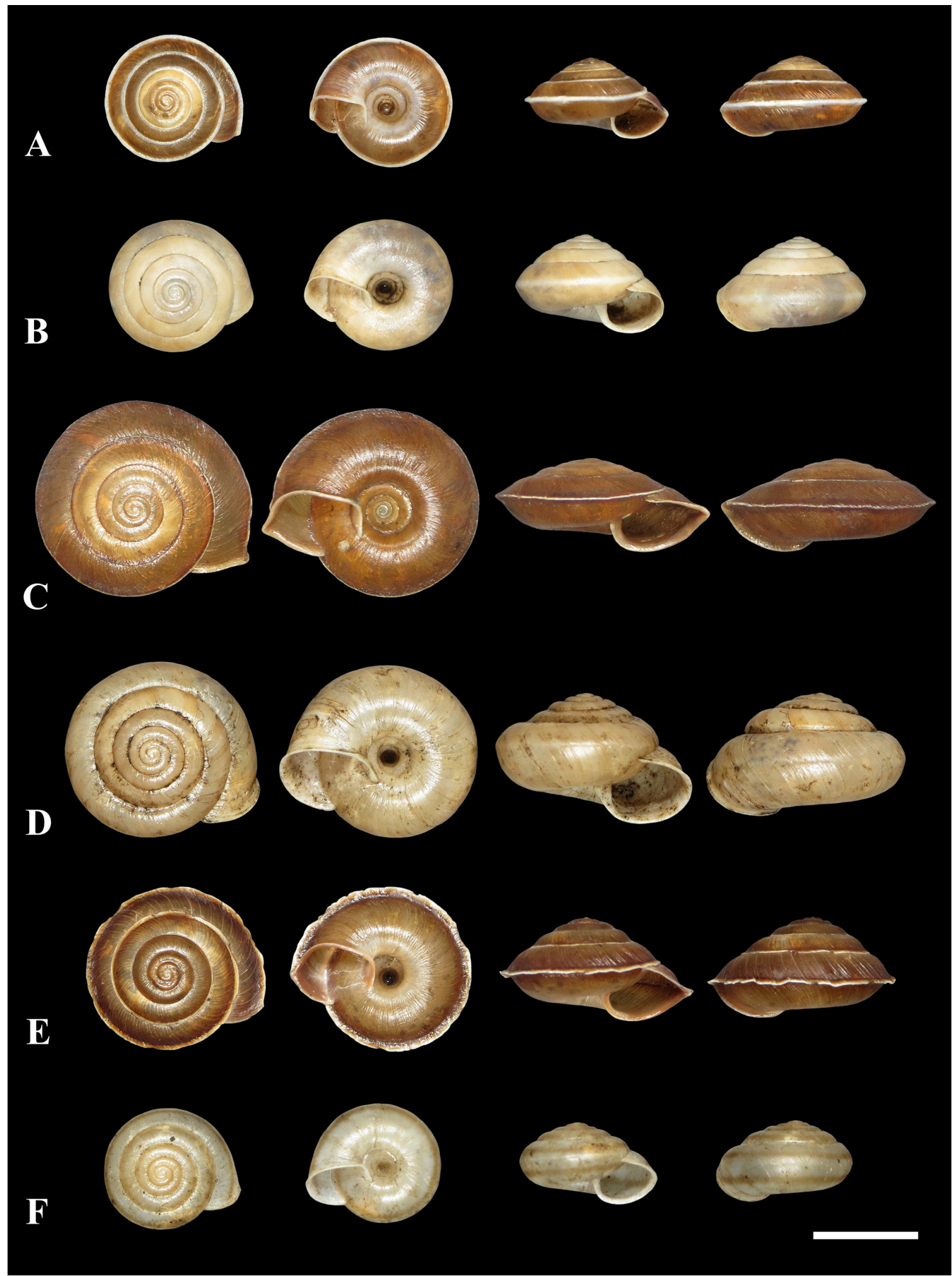

Fig. 3. External shell morphology of Landouria spp. from northeastern Thailand. A. Landouria circinata sp. nov., holotype (NHMSU-00023). B. L. tuberculata sp. nov., holotype (NHMSU-00025). C. L. trochomorphoides sp. nov., holotype (NHMSU-00027). D. L. chloritoides sp. nov., holotype (NHMSU-00029). E. L. elegans sp. nov., holotype (NHMSU-00032). F. L. diplogramma (Möllendorff, 1902) comb. nov. (NHMSU-00034). Scale bar $=10 \mathrm{~mm}$. 

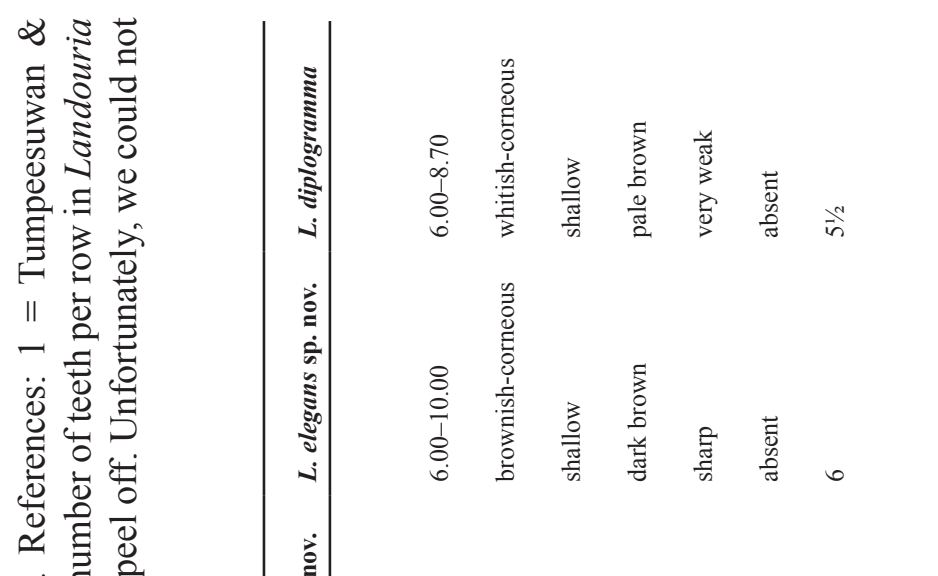

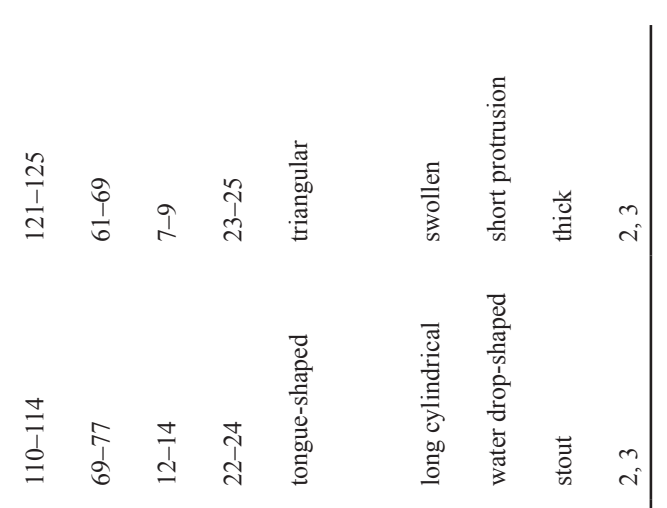

至忿

॥

$\ddot{\mathrm{D}} \stackrel{0}{0}$

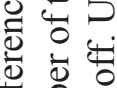

总

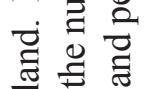

寻 范

듈

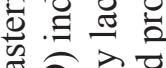

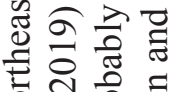

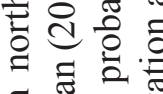

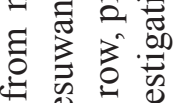

슬.

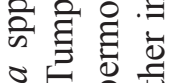

园是言

\& ㄷำ

ङ

फ吉节

द छี छ

氙焉寻

空

焉害

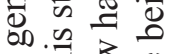

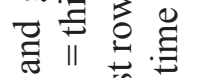

तn

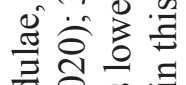

चี ते 章产

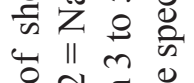

응

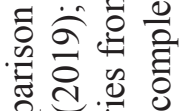

苛 表 
NAHOK B. et al., The genus Landouria from northeastern Thailand

\section{Distribution}

Landouria circinata sp. nov. is known only from the type locality.

Landouria tuberculata sp. nov.

urn:1sid:zoobank.org:act:84133944-D5C9-49A3-9997-8E1C7B335938

Figs 3B, 4B, 5B, 6D-F; Tables 1-4

\section{Diagnosis}

Shell moderately keeled, with numerous tiny tubercles on shell surface (Fig. 4B). Flagellum like a short protrusion with a pointed tip, penis swollen, base of gametolytic sac narrow. Radula with slender, lanceolate central teeth.

\section{Etymology}

The specific epithet 'tuberculata' refers to the shell sculpture consisting of numerous tiny tubercles (Fig. 4B).

\section{Type material}

\section{Holotype}

THAILAND • shell $(\mathrm{SH}=9.6 \mathrm{~mm}, \mathrm{SW}=14.4 \mathrm{~mm}, \mathrm{AH}=5.2 \mathrm{~mm}, \mathrm{AW}=5.5 \mathrm{~mm}, \mathrm{UW}=3.5 \mathrm{~mm})$; Loei Province, Phu Rua District, Wat Thepnimit; 17²6'15.09" N, 101¹6'41.46" E; alt. 647 m; 23 Sep. 2017; B. Nahok, K. Tanmuangpak and U. Chanlabut leg.; NHMSU-00025. (Fig. 3B)

\section{Paratypes}

THAILAND • 10 shells, 7 living specs; same collection data as for holotype; GenBank No. MN449402 and MZ435747; NHMSU-00026.

\section{Description}

Shell (Fig. 3B, Table 1). Dextral, medium-sized, tightly coiled, with $6 \frac{1}{2}$ slightly convex whorls. Suture rather shallow, apex obtuse with high conical spire. Body whorl angular, with tubercles all over its surface, without distinct incised spiral lines. Colour red brown in living specimens (Fig. 4B), empty shells are paler (Fig. 3B). Umbilicus deep and wide. Aperture obliquely oval, reflexed, and slightly thickened.

Genital system $(n=3)$ (Fig. 5B, Table 4). Penis cylindrical, swollen in the middle part, internally with rather wavy, corrugated longitudinal pilasters and a short, hollow verge with 2-3 lobes around its opening. Epiphallus evenly cylindrical, as long as penis. Flagellum like a short protrusion with a pointed tip, without nodes, internally with longitudinal slender pilasters. Vas deferens cylindrical, narrow, entering in the lower half of the flagellum. Vagina relatively short, internally with five corrugated longitudinal pilasters. Free oviduct very short. Gametolytic sac slightly thicker at base, with a long, narrow and thin cylindrical tube, and at its distal end a small, swollen spherical sac. Prostate gland very long. Uterus long and thin.

Radula $(\mathrm{n}=3)$. Comprises 126-130 transverse rows with 79-87 teeth per row; radular formula: $(28-$ 30)-(11-13)-1-(11-13)-(28-30). Central tooth symmetric, slender lanceolate, and unicuspid (Fig. 6D). Lateral teeth larger than the central tooth, lanceolate, bicuspid, with large endocone and sharp cusp (Fig. 6D). Marginal teeth tricuspid, with small sharp endocone; large, slender mesocone; and small v-shaped ectocone with two cusps (Fig. 6E-F). 

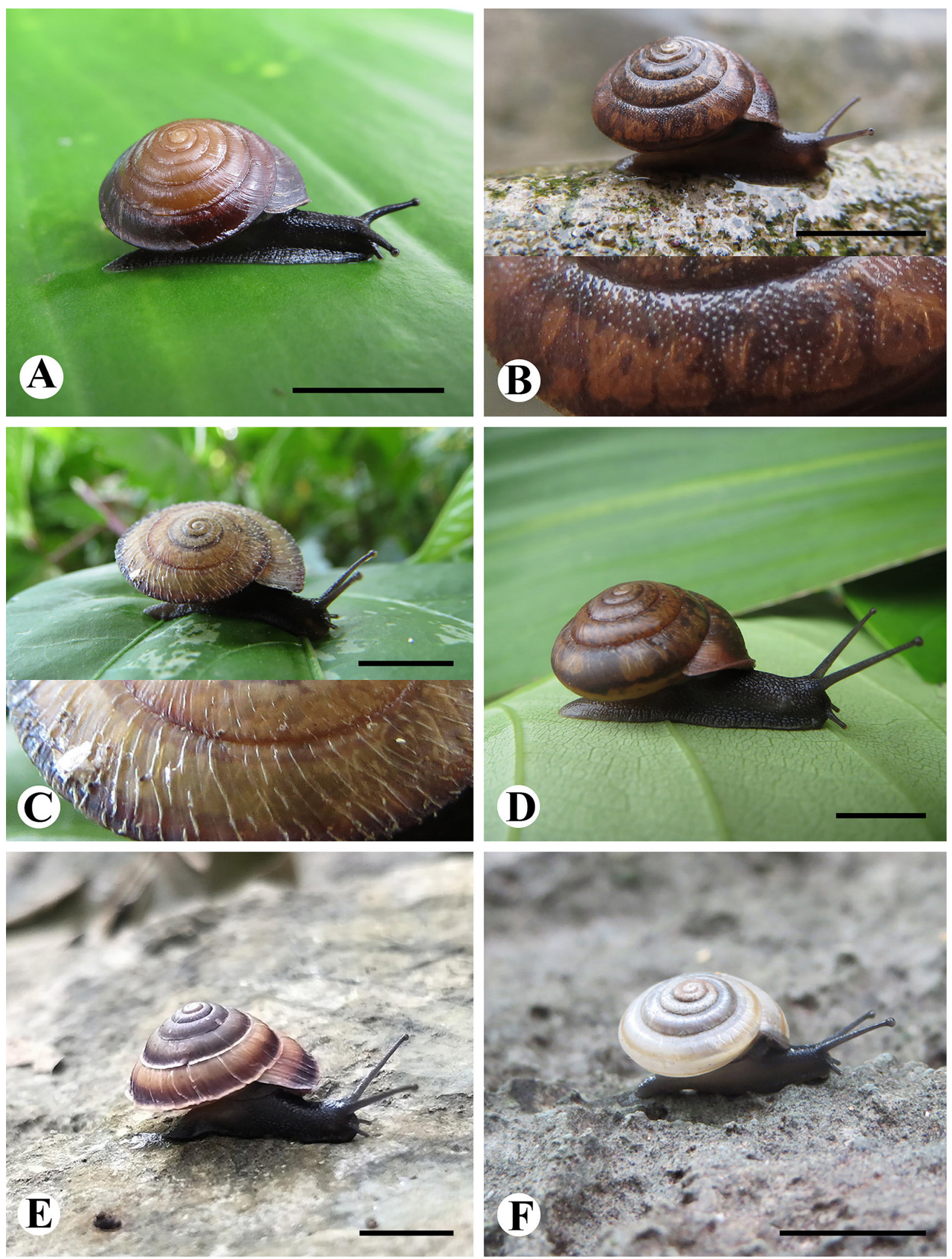

Fig. 4. Living adults of Landouria spp. from northeastern Thailand. A. Landouria circinata sp. nov. B. L. tuberculata sp. nov. C. L. trochomorphoides sp. nov. D. L. chloritoides sp. nov. E. L. elegans sp. nov. F. L. diplogramma (Möllendorff, 1902) comb. nov. Scale bars $=10 \mathrm{~mm}$. 
NAHOK B. et al., The genus Landouria from northeastern Thailand

\section{Remarks}

Landouria tuberculata sp. nov. differs from other Thai species of Landouria, by the shell sculpture of numerous tiny tubercles (Fig. 4B). Lateral teeth of radula bicuspid and lanceolate (Fig. 6D-E).

\section{Distribution}

Landouria tuberculata sp. nov. is currently only known from the area surrounding Phu Rua National Park, Phu Rua District, Loei Province, Thailand.

Landouria trochomorphoides sp. nov. urn:lsid:zoobank.org:act:B7DBFB2E-E7BF-46E5-AFB5-1B45CA4072DE

Figs $3 \mathrm{C}, 4 \mathrm{C}, 5 \mathrm{C}, 6 \mathrm{G}-\mathrm{I}$; Tables $1-4$

\section{Diagnosis}

Shell with rather low spire, sharply keeled, with radial scaly processes (Fig. 4C). Basal portion of flagellum thickened, tapering towards tip; penis narrow and cylindrical; base of gametolytic sac narrow. Radula, with lanceolate central and lateral teeth.

\section{Etymology}

The specific epithet 'trochomorphoides' refers to the conchological similarity between the shell of the new species and that of the land snail genus Trochomorpha Albers, 1850 (Trochomorphidae Möllendorf, 1890).

\section{Type material}

\section{Holotype}

THAILAND • shell $(\mathrm{SH}=10.0 \mathrm{~mm}, \mathrm{SW}=21.3 \mathrm{~mm}, \mathrm{AH}=7.4 \mathrm{~mm}, \mathrm{AW}=9.1 \mathrm{~mm}, \mathrm{UW}=6.2 \mathrm{~mm})$; Loei

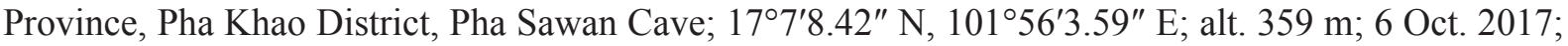
B. Nahok, S. Tumpeesuwan and C. Tumpeesuwan leg.; NHMSU-00027. (Fig. 3C)

\section{Paratypes}

THAILAND • 17 shells, 9 living specs; same collection data as for holotype; GenBank No. MN449403 and MZ435748; NHMSU-00028.

\section{Description}

Shell (Fig. 3C, Table 1). Dextral, relatively large-sized. Whorls six, suture shallow, spire only slightly elevated. Protoconch with radially elongated scars. Body whorl sharply keeled, brownish-corneous with a brown zone at periphery, scaly processes all over shell surface (Fig. 4C). Umbilicus moderately deep and very wide. Aperture lip rhombic, peristome reflexed, and expanded.

Genital system ( $n=3$ ) (Fig. 5C, Table 4). Penis slightly longer than vagina, slender cylindrical, internally with parallel, transverse robust folds; verge absent. Epiphallus slender cylindrical with thickened end. Flagellum as long as epiphallus, basal portion thick and progressively tapering towards tip, without nodes, inner surface smooth. Vas deferens is a thin cylindrical tube, entering epiphallus apically. Vagina thinner than penis, internally with parallel, transverse robust folds. Free oviduct very short. Gametolytic sac slightly narrower at base, with a long narrow cylindrical tube, and a small, oval sac at the distal end. Prostate gland and uterus very long.

Radula $(\mathrm{n}=3)$. Comprises 107-111 transverse rows with 65-73 teeth per row; radular formula: (2426)-(8-10)-1-(8-10)-(24-26). Central tooth unicuspid triangular (Fig. 6G). Lateral teeth short and broad leaf-shaped, bicuspid, larger than central tooth, with small ectocone (Fig. 6G-H). Marginal teeth 
asymmetric, tricuspid with small endocone; mesocone large and long, with curved margins; ectocone triangular with two to four cusps (Fig. 6H-I).

\section{Remarks}

Landouria trochomorphoides sp. nov. differs from other taxa by its very large, rather flat, sharply keeled shell with scaly surface (Figs 3C, 4C). Lateral teeth of radula are stout bicuspid (Fig. 6G-I), genital system is small and slim (Fig. 5C).

\section{Distribution}

Landouria trochomorphoides sp. nov. is known only from the type locality.

Landouria chloritoides sp. nov. urn:1sid:zoobank.org:act:740CA614-D17B-47A3-A719-7DFC7D2CE2D5

Figs 3D, 4D, 5D, 6J-L; Tables 1-4

Landouria sp.1 - Ounchareon 2015: 29-32, 44-50, 54-56, 59, 61, figs 4.2c, 4.3c, 4.4. 4.5i-1, 5.5, 5.7.

Landouria sp.2 - Buddharaksa 2016: 37-38, 41-42, figs 4.19, 4.20, 5.1, 5.2.

Landouria sp.4 - Yingkhamhang 2016: 25-26, 39-41, 43-45, 49-52, figs 4.7, 4.8, 4.21d, 4.22d, 5.3a, 5.4a.

\section{Diagnosis}

Shell shape similar to that of the genus Chloritis Beck, 1837 (Camaenidae), but with last whorl stout and usually slightly angular, peripheral keel blunt, suture deep, aperture oval and oblique. Flagellum small ovate, penis very large and stout compared to vagina; vagina and free oviduct short (Fig. 5D). Radula with lanceolate teeth.

\section{Etymology}

The specific epithet 'chloritoides' refers to the conchological similarity between the shell of the new species and that of the camaenid genus Chloritis.

\section{Type material}

\section{Holotype}

THAILAND • shell $(\mathrm{SH}=12.0 \mathrm{~mm}, \mathrm{SW}=19.0 \mathrm{~mm}, \mathrm{AH}=7.7 \mathrm{~mm}, \mathrm{AW}=7.3 \mathrm{~mm}, \mathrm{UW}=3.9 \mathrm{~mm})$; Khon Kaen Province, Chum Phae District, Wat Thep Udom Wanaram; 16 $45^{\prime 2} 9^{\prime \prime}$ N, 101 ${ }^{\circ} 57^{\prime} 55.03^{\prime \prime}$ E; alt. 406 m; 9 Jun. 2017; B. Nahok, S. Tumpeesuwan and C. Tumpeesuwan leg.; NHMSU-00029. (Fig. 3D)

\section{Paratypes}

THAILAND • 8 shells, 14 living specs; same collection data as for holotype; GenBank No. MN449404 and MZ435749; NHMSU-00030.

\section{Other material examined}

THAILAND • 4 shells, 8 living specs; North East, Khon Kaen Province, Chum Phae District, Pu Lup Cave; $16^{\circ} 49^{\prime} 49.78^{\prime \prime}$ N, 10159'9.97" E; alt. 336 m; NHMSU-00031.

\section{Description}

Shell (Fig. 3D, Table 1). Dextral, somewhat depressed, relatively large-sized. Whorls 61/2, suture deep, apex obtuse, and moderately depressed, with low conical spire. Body whorl rounded, slightly keeled, red-brown in living specimens (Fig. 4D), empty shells are paler (Fig. 3D). Umbilicus very deep and wide. Aperture almost circular, with slightly thickened and weakly expanded lip. 

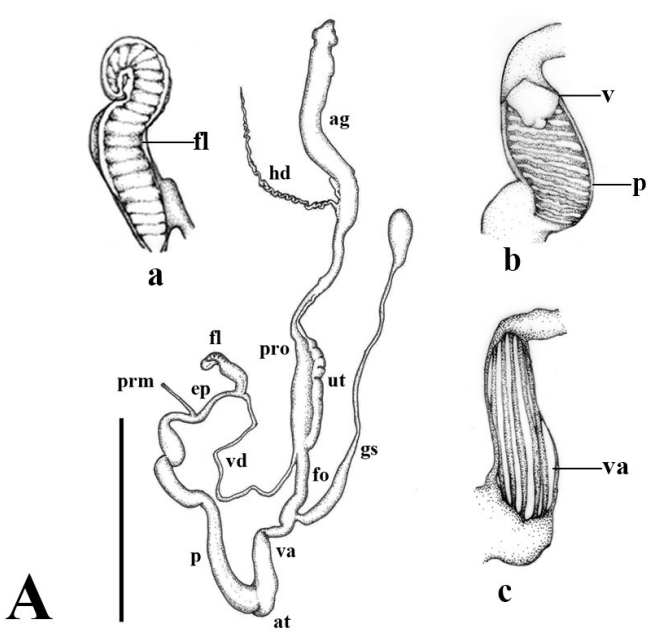

b
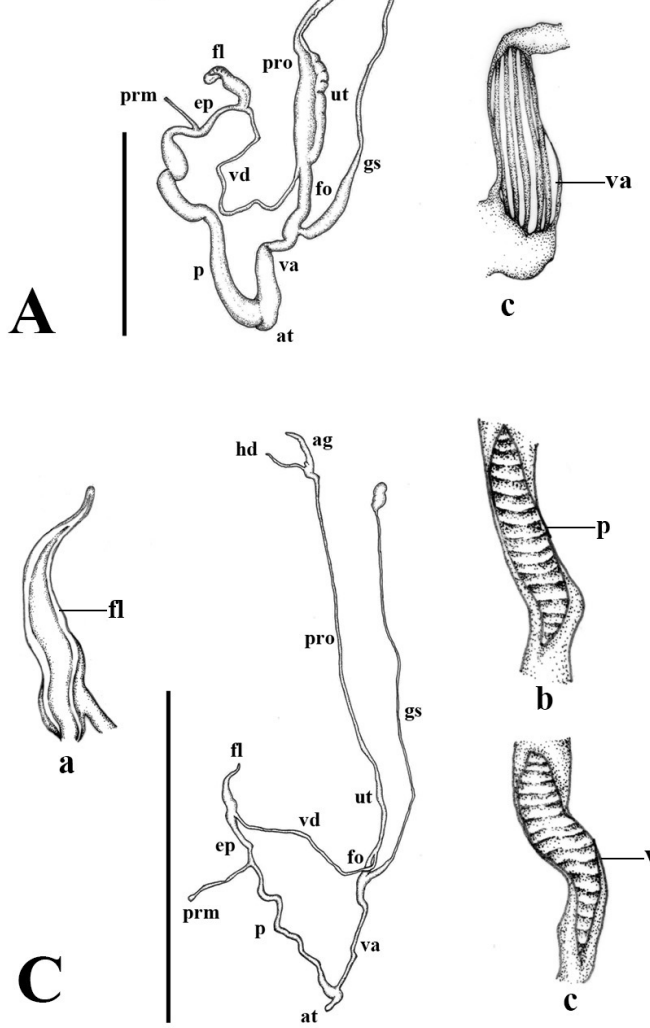

C
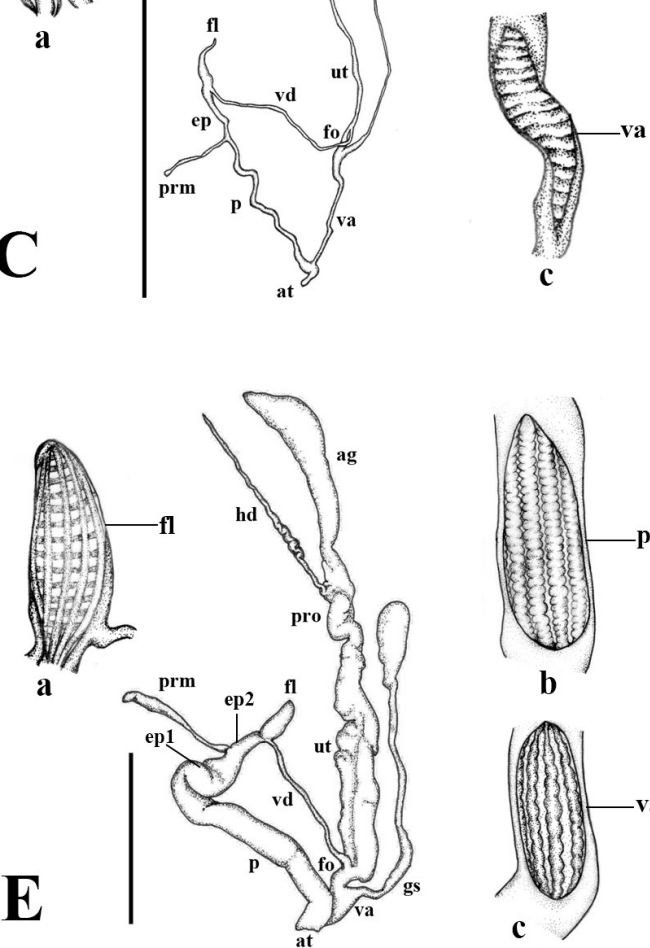
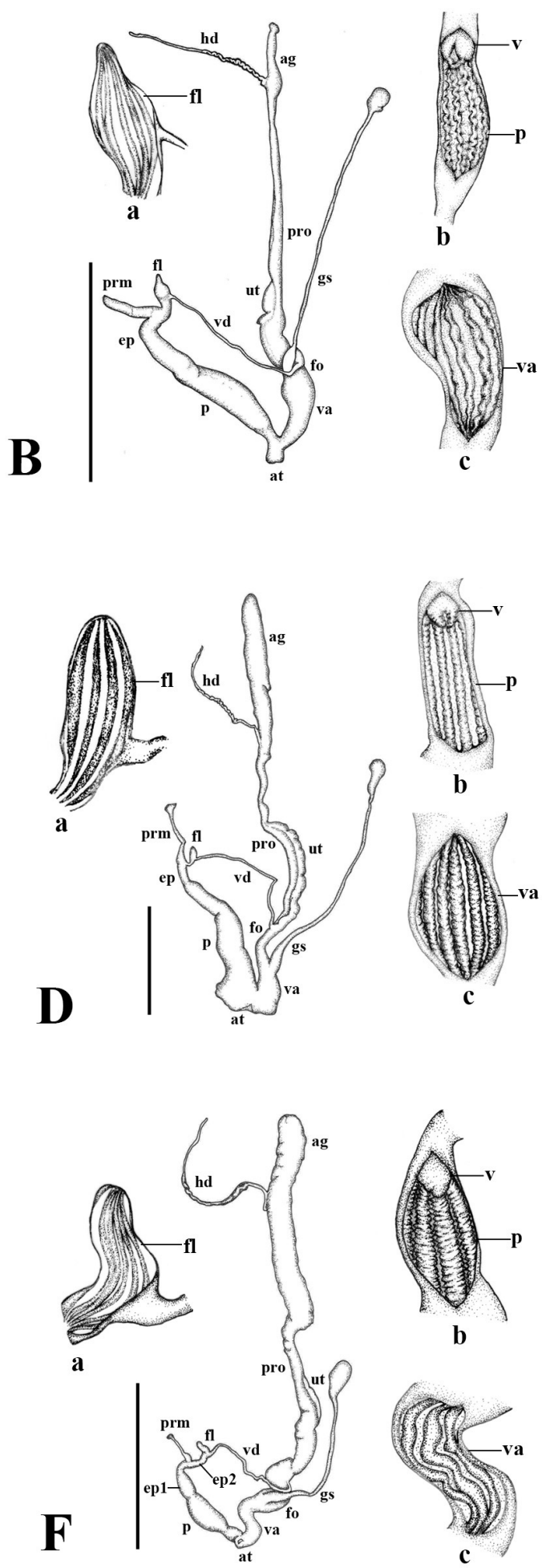

Fig. 5. Illustrations of the genital system of Landouria spp. from northeastern Thailand. A. Landouria circinata sp. nov., paratype (NHMSU-00024). B. L. tuberculata sp. nov., paratype (NHMSU-00026). C. L. trochomorphoides sp. nov., paratype (NHMSU-00028). D. L. chloritoides sp. nov., paratype (NHMSU-00030). E. L. elegans sp. nov., paratype (NHMSU-00033). F. L. diplogramma (Möllendorff, 1902) comb. nov. (NHMSU-00034). Internal sculpture of $a=$ flagellum; $b=$ penis; $c=$ vagina. Scale bars $=10 \mathrm{~mm}$. 
Genital system $(\mathrm{n}=3)$ (Fig. 5D, Table 4). Penis very large and stout, longer than vagina, cylindrical, gradually tapering towards epiphallus, internally with six rather thick, corrugated longitudinal pilasters; opening of the short, grooved verge surrounded by 2-3 lobes. Epiphallus short and thick. Flagellum short, elongate ovate, without nodes, internally with three large longitudinal pilasters. Vas deferens long and slender, entering in the lower half of the flagellum. Vagina short, as long as free oviduct, internally with seven, corrugated longitudinal pilasteres varying in size. Gametolytic sac thickened at base, with a long narrow cylindrical tube, and a small oval sac at distal end. Uterus swollen, prostate gland long.

Radula $(\mathrm{n}=3)$. Comprises $125-129$ transverse rows with 75-83 teeth per row; radular formula: (26-28)(11-13)-1-(11-13)-(26-28). Central tooth short lanceolate, symmetric, unicuspid (Fig. 6J). Lateral teeth large and elongated lanceolate (Fig. 6J). Marginal teeth lanceolate, gradually changing from unicuspid to bicuspid and finally tricuspid; endocone small; ectocone slightly oblique, with wide triangular notch and two to four lateral cusps (Fig. 6K-L).

\section{Remarks}

Landouria chloritoides sp. nov. can be distinguished from other species of Landouria in Thailand by its conchological similarity to the genus Chloritis and its much larger and stout penis (Fig. 5D). The radula of $L$. chloritoides sp. nov. is similar to that of $L$. tuberculata sp. nov. but differs by its unicuspid lateral teeth (Fig. 5J) vs the bicuspid lateral teeth of L. tuberculata sp. nov.

\section{Distribution}

Landouria chloritoides sp. nov. is currently known only from the limestone area around Phu Pha Man National Park, Chum Phae District, Khon Kaen Province, Thailand.

Landouria elegans sp. nov. urn:1sid:zoobank.org:act:6A33A2BA-7197-4C1E-AEB3-D7815F8A05AC

Figs 3E, 4E, 5E, 6M-O; Tables 1-4

Landouria sp.3 - Yingkhamhang 2016: 23-24, 39-45, 47-48, 61, 74, figs 4.5, 4.6, 4.21-4.23c, 5.1c, 5.2c.

\section{Diagnosis}

Shell similar to Landouria circinata sp. nov., but with a sharper and more prominent keel at the periphery and dark brown zones on the periphery, just above and below the keel. Flagellum droplet shaped, penis long and cylindrical, vagina and free oviduct very short. Radula with elongate tongue-shaped central and lateral teeth.

\section{Etymology}

The specific epithet 'elegans' (Latin for 'magnificent') refers to the beauty of the shell.

\section{Type material}

\section{Holotype}

THAILAND • shell (SH 10.0 = mm, SW $17.7=\mathrm{mm}, \mathrm{AH}=6.4 \mathrm{~mm}, \mathrm{AW}=7.1 \mathrm{~mm}, \mathrm{UW}=3.6 \mathrm{~mm}) ;$ Khon Kaen Province, Phu Pha Man District, Phu (mountain) Hua Chang; 16 $39^{\prime} 10.54^{\prime \prime}$ N, 101 ${ }^{\circ} 48^{\prime} 6.67^{\prime \prime}$ E; alt. 305 m; 3 May 2018; B. Nahok, S. Tumpeesuwan and C. Tumpeesuwan leg.; NHMSU-00032. (Fig. 3E)

\section{Paratypes}

THAILAND • 11 shells; 9 living specs; same collection data as for holotype; GenBank No. MN449408 and MZ435751; NHMSU-00033. 


\section{Description}

Shell (Fig. 3E, Table 1). Dextral, conical, relatively large-sized. Whorls 6. Protoconch with radially elongated wrinkles. Suture rather shallow, apex obtuse depressed, with rather high conical spire. Last whorl with a sharp keel that is distinctly bent downwards. Colour brownish-corneous with a dark brown zone bordering the keel at the periphery. Umbilicus very deep and wide. Apertural lip thickened, rounded rhombic.

Genital system $(n=3)$ (Fig. 5E, Table 4). Penis longer than vagina, cylindrical, internally with four corrugated, longitudinal pilasters; verge absent. Epiphallus shorter than penis, distal part (ep2) small, whereas proximal part (ep1) is swollen. Flagellum droplet-shaped, without nodes, internally with four corrugated, longitudinal pilasters. Vas deferens long, cylindrical, proximal part that connects to free oviduct somewhat thicker than distal part, entering the flagellum at its base. Vagina very short, internally with five corrugated longitudinal pilasters. Free oviduct shorter than vagina. Proximal part of gametolytic sac rather stout, but tapering to become a slender tube with large oval sac at distal end. Uterus and prostate gland very long and large.

RAdUla $(\mathrm{n}=3)$. Comprises 110-114 transverse rows with 69-77 teeth per row; radular formula: $(22-24)$ (12-14)-1-(12-14)-(22-24). Central and lateral teeth unicuspid, tongue-shaped. Central tooth smaller and shorter than lateral teeth (Fig. 6M-N). Marginal teeth asymmetric, tricuspid with small endocone; mesocone large with curved margins; ectocone triangular and located at tooth base (Fig. $6 \mathrm{~N}-\mathrm{O}$ ).

\section{Remarks}

Landouria elegans sp. nov. is conchologically quite similar to L. circinata sp. nov. and L. strobiloides, from which it differs by its sharper and more distinct keel with its downward bent rim (Fig. 3A vs Fig. 3E). The radula of $L$. elegans sp. nov. resembles that of $L$. circinata sp. nov., but central tooth and lateral teeth of L. elegans sp. nov. are longer and more slender than in L. circinata sp. nov. (Fig. 6A-C vs Fig. 6M-O). Epiphallus of L. elegans sp. nov. is similar to that of L. chloritoides sp. nov., but in L. elegans sp. nov. it is larger and connects with the vas deferens near the flagellum base (Fig. 5D vs Fig. 5E).

\section{Distribution}

Landouria elegans sp. nov. is known only from the type locality.

Landouria diplogramma (Möllendorff, 1902) comb. nov.

Figs 3F, 4F, 5F, 6P-R; Tables 1-4

Plectotropis diplogramme Möllendorff, 1902: 158-159.

Ganesella diplogramme - Panha 1996: 36.

Aegista (Plectotropis) diplogramma - Hemmen \& Hemmen 2001: 47.

Thaitropis sp. - Sutcharit et al. 2017: 249, fig. 6-32e.

\section{Diagnosis}

Shell small, low-conical, weakly keeled, with a slightly elevated spire, whitish corneous with a pale brown band above periphery. Flagellum like a short protrusion, with rounded tip. Penis short swollen. Central and the first few lateral radular teeth triangular.

\section{Material examined}

THAILAND - 29 shells, 14 living specs; Nakhon Ratchasima Province, Pak Chong District, Wat Thep Phithak Punnaram; 14³6'54.57" N, 101 ${ }^{\circ} 15^{\prime} 55.25^{\prime \prime}$ E; alt. 451 m; 23 Jun. 2017; B. Nahok and U. Chanlabut leg.; GenBank No. MN449411 and MZ435752; NHMSU-00034. (Fig. 3F) 


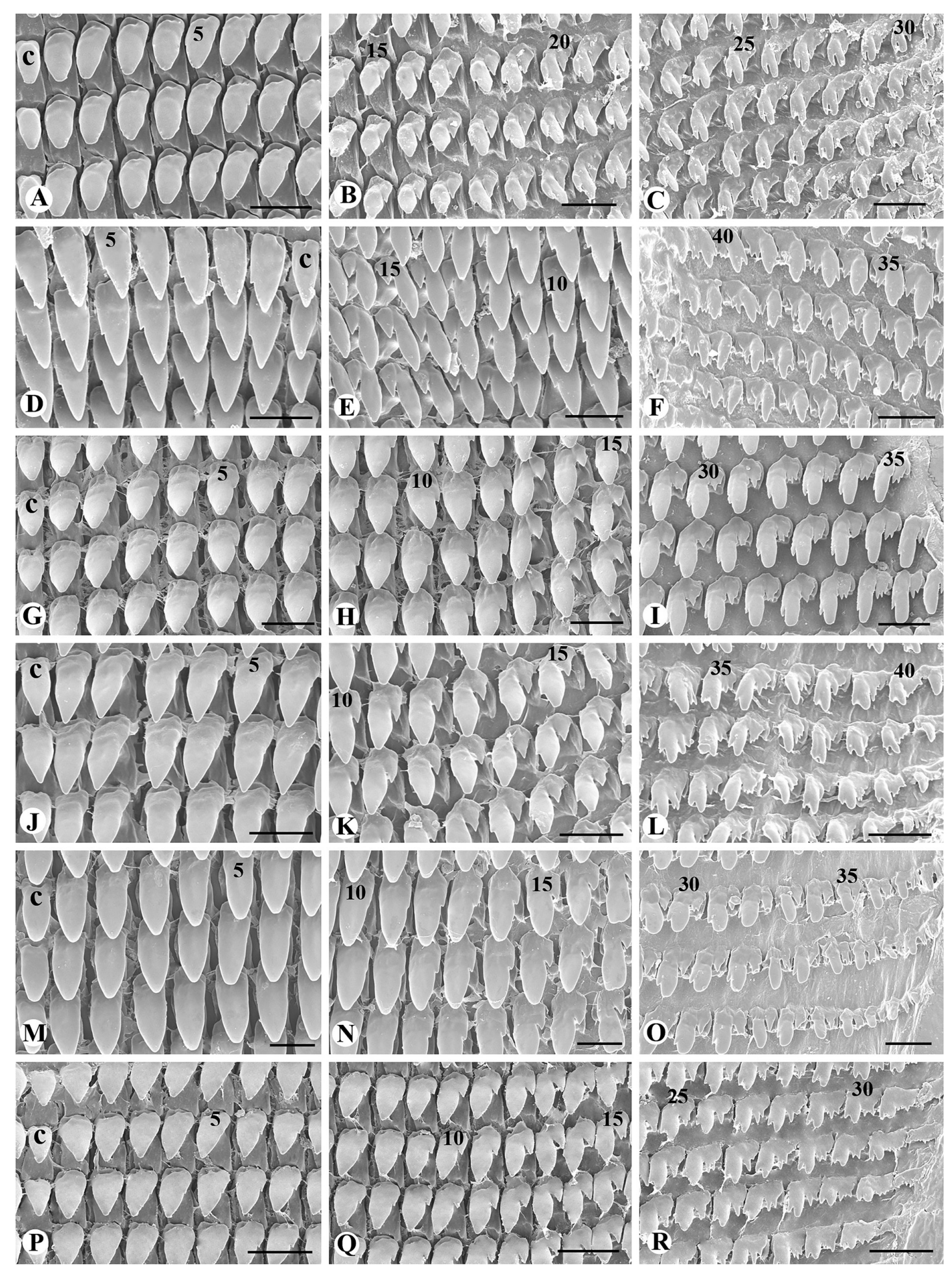

Fig. 6. Radula morphology of Landouria spp. from northeastern Thailand. A-C, G-R. Right side of central teeth. D-F. Left side of central teeth. A-C. Landouria circinata sp. nov., paratype (NHMSU-00024). D-F. L. tuberculata sp. nov., paratype (NHMSU-00026). G-I. L. trochomorphoides sp. nov., paratype (NHMSU-00028). J-L. L. chloritoides sp. nov., paratype (NHMSU-00030). M-O. L. elegans sp. nov., paratype (NHMSU-00033). P-R. L. diplogramma (Möllendorff, 1902) comb. nov. (NHMSU-00034). Numbers indicate order of lateral and marginal teeth. Abbreviation: $\mathrm{c}=$ central tooth. Scale bars $=$ $25 \mu \mathrm{m}$. 


\section{Description}

SheLl (Fig. 3F, Table 1). Dextral, small, depressed conical. Whorls 51/2, suture rather shallow, apex obtuse and depressed, whitish corneous, with a pale brown peripheral band. Protoconch almost smooth. Umbilicus moderately deep and wide. Aperture oval oblique, with thin, solid, and weakly reflected lip.

Genital system $(\mathrm{n}=3)$ (Fig. 5F, Table 4). Penis divided into two short portions, the portion that connects to epiphallus is swollen and the portion that connects to atrium is constricted; internally with three corrugated longitudinal pilasters; with short, rather rounded verge. Flagellum like a short protrusion, internally with two narrow longitudinal pilasters. Vas deferens long, cylindrical, entering the epiphallus at base. Free oviduct very short. Vagina twice as long as free oviduct, internally with five thick, corrugated longitudinal pilasters. Proximal part of gametolytic sac slightly thicker than the cylindrical tube, with a medium-sized oval sax at distal end. Uterus and prostate gland long.

RADULA ( $n=3)$. Comprises 121-125 transverse rows with 61-69 teeth per row; radular formula: (23-25)(7-9)-1-(7-9)-(23-25). Central tooth usually symmetric, unicuspid, triangular (Fig. 6P). Lateral teeth longer and larger than central teeth, bicuspid, ectocone small, with sharp cusp (Fig. 6Q). Marginal teeth gradually changing from bicuspid to tricuspid, small endocone; mesocone large lanceolate; ectocone triangular with two to four tiny cusps (Fig. 6R).

\section{Remarks}

Specimens deposited in the Leiden Museum, The Netherlands, RMNH.MOL.309867 and RMNH. MOL.309851 (https://images.app.goo.gl/PgrpqKaWuSrgjdvN9), are identified as Plectotropis diplogramme Möllendorff, 1902. These specimens appear identical to specimens from Khao See Siad Ah in Nakhon Ratchasima Province, therefore we used the name "Landouria diplogramma (Möllendorff, 1902)" for this species in the present study. Landouria diplogramma differs from other Thai species of Landouria by its relatively small lustrous shell without peripheral keel, but with a pale brown band present above periphery (Figs 3F, 4F). Its radular teeth are relatively short (Fig. 6P-R). Its penis and flagellum are relatively short (Fig. 5F).

The genus Thaitropis Schileyko, 2004 was recently reported in Thailand (Schileyko 2004; Sutcharit et al. 2017). Yet, this genus was synonymized with Landouria by Nurinsiyah et al. (2019). Based on the illustration provided by Sutcharit et al. (2017: fig. 6-32e), we identify their Thai Thaitropis sp. as L. diplogramma, because it has the same shell morphology and colours: Plectotropis diplogramme Möllendorff, 1902, RMNH.MOL.309867, and L. diplogramma (Möllendorff, 1902) from Khao See Siad Ah, Nakhon Ratchasima (NHMSU-00034) (Figs 3F, 4F). Unfortunately, the whereabouts of the type specimen of Plectotropis diplogramme are unknown. Yet, it might be deposited in the collections of the Senckenberg Museum in Frankfurt, Germany where it should be looked up and checked in a further study.

\section{Distribution}

Landouria diplogramma was collected by local people in the mountain range known as Khao See Siad Ah, Pak Chong District, Nakhon Ratchasima Province, Thailand. Other reported localities comprise Bangkok, Hinlap, Muoklek, Kanburi (Kanchanaburi) (Möllendorff 1902). 


\section{Key to species by shell characters of Landouria species in northeastern Thailand}

Finally, in order to facilitate future field research, we provide a dichotomous key for the identification of the currently known Landouria species in northeast Thailand.

1. Shell lustrous, peripheral keel absent, brown band present

L. diplogramma (Möllendorff, 1902) comb. nov.

- Shell not lustrous, peripheral keel absent, brown band absent

2. Peripheral keel blunt L. chloritoides sp. nov.

- Peripheral keel sharp 3

3. Peripheral keel slightly sharp, shell surface with numerous tiny tubercles ....L. tuberculata sp. nov.

- Peripheral keel very sharp, shell surface without tubercles .....

4. Shell relatively large with low spire, shell surface with radial scaly processes

L. trochomorphoides sp. nov.

- Shell relatively moderate in size with high spire, shell surface without radial scaly processes ....... 5

5. Keel more sharp and distinct with its downward bent rim L. elegans sp. nov.

- Keel sharp, without downward bent rim 6

6. Suture indented, growth line obvious

L. strobiloides C. Tumpeesuwan \& S. Tumpeesuwan, 2019

- Suture not indented, growth line obscure L. circinata sp. nov.

\section{Key to species by genitalia characters of Landouria species in northeastern Thailand}

1. Penis shorter than vagina; flagellum strobilus-like

L. strobiloides C. Tumpeesuwan \& S. Tumpeesuwan, 2019

- Penis longer than vagina; flagellum non-strobilus-like

2. Flagellum circinate L. circinata $\mathrm{sp}$. nov.

- Flagellum like a short protrusion, ovate or elongate ovate 3

3. Flagellum elongate ovate, slender towards tip; inner sculpture of flagellum simple L. trochomorphoides sp. nov.

- Flagellum ovate or elongate ovate; inner sculpture of flagellum with longitudinal pilasters 4

4. Vagina shorter than free oviduct; inner penis without verge L. elegans sp. nov.

- Vagina as long or longer than free oviduct; inner penis with verge 5

5. Vagina as long as free oviduct L. chloritoides sp. nov.

- Vagina longer than free oviduct 6

6. Inner wall of penis with wavy, corrugated slender longitudinal pilasters; short, hollow verge

L. tuberculata sp. nov.

- Inner wall of penis with stout, longitudinal, zigzag, pilasters; short, rounded verge .. L. diplogramma (Möllendorff, 1902) comb. nov. 


\section{Discussion}

Previously, Thai land snails with small, depressed conical shells were usually identified as Aegista Albers, 1850 (Bradybaenidae), based on their shell morphology only. Yet, recent studies of the genital system of these species showed that they lacked a dart apparatus and mucus glands, indicating that they are not species of Aegista, but rather belong in the genus Landouria (Camaenidae) (e.g., Tumpeesuwan \& Tumpeesuwan 2019).

Phylogenetic analysis divided Landouria into two clades in accordance with the geographical boundaries between the Mainland Southeast Asia, Sumatra, and Timor-Leste. In Thailand the species form a monophyletic group, with four species endemic to Loei Province. These four species were discovered on different isolated limestone and sandstone hills or mountains, so their distribution ranges do not overlap. Furthermore, each hill or mountain was surrounded by geographic barriers, such as floodplains or other unsuitable habitats. The present study illustrates that in northeastern Thailand there remains a substantial amount of overlooked malacological diversity to be discovered. Hence further taxonomic research on the malacofauna of this region will undoubtedly uncover still many more undescribed terrestrial snail species.

\section{Acknowledgements}

This research project was financially supported by Mahasarakham University (Fast Track 2021) and the National Research Council of Thailand (FY2019 Thesis Grant for Doctoral Degree Students). Partial support was also provided by the Science Achievement Scholarship of Thailand (SAST). The authors are grateful for help with undertaking the survey and sampling the materials in the field by Kitti Tanmuangpak and Utain Chanlabut. We wish to express sincere thanks to Nual-anong Wichaikul and the staff of the Centre for Scientific and Technological Equipment, Suranaree University of Technology, for their help with sample processing and SEM work. We would like to thank Jolyon Dodgson, native English speaker, who helped check the language in the manuscript. We deeply thank Thierry Backeljau, Liew Thor Seng, and three anonymous reviewers for their valuable comments and suggestions. The Animal Care and Use Protocol Review No. IACUC-MSU-029/2018.

\section{References}

Akaike H. 1974. A new look at the statistical model identification. IEEE Transactions on Automatic Control 19 (6): 716-723. https://doi.org/10.1109/TAC.1974.1100705

Buddharaksa W. 2016. Reproductive Anatomy of Some Land Pulmonate Snails in Northeastern Thailand. Unpublished Bachelor's Degree Science Project. Department Faculty of Science, Mahasarakham University, Maha Sarakham. [In Thai with English Abstract.]

Budha P.B., Naggs F. \& Backeljau T. 2015. Annotated checklist of the terrestrial gastropods of Nepal. ZooKeys 492: 1-48. https://doi.org/10.3897/zookeys.492.9175

Chiba S. 1999. Accelerated evolution of land snails Mandarina in the oceanic Bonin Islands: evidence from mitochondrial DNA sequences. Evolution 53 (2): 460-471.

https://doi.org/10.1111/j.1558-5646.1999.tb03781.x

Darriba D., Taboada G.L., Doallo R. \& Posada D. 2012. jModelTest 2: more models, new heuristics and parallel computing. Nature Methods 9 (8): 772. https://doi.org/10.1038/nmeth.2109

Dharma B. 2015. A new species of Landouria Godwin-Austen 1918 from Java, Indonesia (Gastropoda, Bradybaenidae). Schriften zur Malakozoologie 28: 7-12.

Folmer O., Black M., Hoeh W., Lutz R.A. \& Vrijenhoek R. 1994. DNA primers for amplification of mitochondrial cytochrome c oxidase subunit I from diverse metazoan invertebrates. Molecular Marine Biology and Biotechnology 3: 294-299. 
Geiger D.L., Marshall B.A., Ponder W.F., Sasaki T. \& Warén A. 2007. Techniques for collecting, handling, preparing, storing and examining small molluscan specimens. Molluscan Research 27 (1): $1-50$.

Hall T. 1999. BioEdit: a user-friendly biological sequence alignment editor and analysis program for Windows 95/98/NT. Nucleic Acids Symposium Series 41: 95-98.

Hall T. 2001. BioEdit version 5.0.6. North Carolina State University, Department of Microbiology, Raleigh.

Hemmen J. \& Hemmen C. 2001 Aktualisierte Liste der terrestrischen Gastropoden Thailands. Schriften zur Malakozoologie 18: 35-70.

Hirano T., Kameda Y., Kimura K. \& Chiba S. 2014. Substantial incongruence among the morphology, taxonomy, and molecular phylogeny of the land snails Aegista, Landouria, Trishoplita, and Pseudobuliminus (Pulmonata: Bradybaenidae) occurring in East Asia. Molecular Phylogenetics and Evolution 70: 171-181. https://doi.org/10.1016/j.ympev.2013.09.020

Hutton T. \& Benson W.H. 1838. On the land and fresh-water shells of the western Himalaya. Journal of the Asiatic Society of Bengal 7: 211-218.

Köhler F., Shea M. \& Kessner V. 2018. Two new species of Landouria Godwin-Austen, 1918 from Timor-Leste (Stylommatophora, Camaenidae). Molluscan Research 39 (3): 253-264.

https://doi.org/10.1080/13235818.2018.1557780

Kumar S., Stecher G., Li M., Knyaz C. \& Tamura K. 2018. MEGA X: Molecular Evolutionary Genetics Analysis across computing platforms. Molecular Biology and Evolution 35 (6): 1547-1549. https://doi.org/10.1093/molbev/msy096

Möllendorff O.F. 1902. Neue Arten und Unterarten von Fruhstorfer in Siam gesammelt. Nachrichtsblatt der Deutschen Malakozoologischen Gesellschaft 34 (9-10): 153-160.

Nahok B. 2020. Systematics and Taxonomy of Land Snails Genera Aegista, Thaitropis, Landouria, and Pseudobuliminus in Thailand. Unpublished PhD thesis, Department of Biology, Faculty of Science, Mahasarakham University.

Neiber M.T., Razkin O. \& Hausdorf B. 2017. Molecular phylogeny and biogeography of the land snail family Hygromiidae (Gastropoda: Helicoidea). Molecular Phylogenetics and Evolution 111: 169-184. https://doi.org/10.1016/j.ympev.2017.04.002

Nurinsiyah A.S., Neiber M.T. \& Hausdorf B. 2019. Revision of the land snail genus Landouria GodwinAusten, 1918 (Gastropoda, Camaenidae) from Java. European Journal of Taxonomy 526: 1-73. https://doi.org/10.5852/ejt.2019.526

Ounchareon J. 2015. Taxonomy of Land Snail Genus Landouria Godwin-Austen, 1918 in Northeastern Thailand. Unpublished Master thesis. Department Faculty of Science, Mahasakham University, Maha Sarakham. [In Thai with English abstract.]

Páll-Gergely B., Hunyadi A. \& Asami T. 2013. A peculiar new species in the genus Landouria GodwinAusten, 1918 from China (Gastropoda: Heterobranchia: Stylommatophora: Camaenidae). Molluscan Research 33: 130-134. https://doi.org/10.1080/13235818.2013.782794

Páll-Gergely B., Hunyadi A. \& Hausdorf B. 2020. A new species of Landouria Godwin-Austen, 1918 (Gastropoda: Stylommatophora: Camaenidae) from Myanmar. Raffles Bulletin of Zoology 68: 379-386. Available from https://kcnhm.nus.edu.sg/app/uploads/2020/01/RBZ-2020-0054.pdf [accessed 1 Sep. 2021].

Panha S. 1996 A checklist and classification of the terrestrial pulmonate snails of Thailand. Walkerana 8 (19): 31-40. 
NAHOK B. et al., The genus Landouria from northeastern Thailand

Posada D. 2008 jModelTest: phylogenetic model averaging. Molecular Biology and Evolution 25: 1253-1256. https://doi.org/10.1093/molbev/msn083

Ramakrishna, Mitra S.C. \& Dey A. 2010. Annotated checklist of Indian land molluscs. Zoological Survey of India 306: 1-359.

Rambaut A. 2012. FigTree Version 1.4.0 Figure Drawing Tool 2006-2012. Institute of Evolutionary Biology, University of Edinburgh. Available from http://tree.bio.ed.ac.uk/software/figtree/ [accessed 1 Sep. 2021].

Richardson L. 1985. Camaenidae: catalog of species. Tryonia 12: 1-479.

Ronquist F., Teslenko M., van der Mark P., Ayres D.L., Darling A., Hohna S., Larget B., Liu L., Suchard M.A. \& Huelsenbeck J.P. 2012. MrBayes 3.2: efficient Bayesian phylogenetic inference and model choice across a large model space. Systematic Biology 61: 539-542.

https://doi.org/10.1093/sysbio/sys029

Schileyko A.A. 2004. Treatise on recent terrestrial pulmonate molluscs. Part 12. Bradybaenidae, Monadeniidae, Xanthonychidae, Epiphragmophoridae, Helminthoglyptidae, Elonidae, Humboldtianidae, Sphincterochilidae, Cochlicellidae. Ruthenica Supplement 2: 1627-1764.

Schileyko A.A. \& Kuznetsov A.G. 1998. Land snails of the genus Landouria Godwin-Austen, 1918 and some other Bradybaenidae of Nepal (Gastropoda, Pulmonata). Ruthenica 8: 43-54.

Stamatakis A. 2014. RAxML version 8: a tool for phylogenetic analysis and post-analysis of large phylogenies. Bioinformatics 30 (9): 1312-1313. https://doi.org/10.1093/bioinformatics/btu033

Sutcharit C., Tongkerd P. \& Panha S. 2017. Land Snails the Invaluable Bio-Resources for the Kingdom of Thailand. The Thailand Research Fund, Bangkok. [In Thai.]

Tanmuangpak K. 2016. Species Diversity, Abundance, Distribution and Habitat Relationship of Land Snails in Phu Pha Lom Limestone Area, Loei Province. Unpublished PhD thesis, Department of Biology, Faculty of Science, Mahasarakham University.

Tanmuangpak K., Tumpeesuwan C. \& Tumpeesuwan S. 2012. Diversity of land snails in Phu Pha Lom Forest Park at Muang District, Loei Province. Journal of Science and Technology Mahasarakham University Special Issue 8: 15-26. [In Thai with English abstract.]

Tumpeesuwan C. \& Tumpeesuwan S. 2019. First verified record of the genus Landouria GodwinAusten, 1918 from Thailand (Gastropoda: Stylommatophora: Camaenidae) with description of a new species. Raffles Bulletin of Zoology 67: 298-305. https://doi.org/10.26107/RBZ-2019-0021

Yingkhamhang A. 2016. Shell Morphology and Reproductive Anatomy of Land Snails Genus Landouria Godwin-Austen, 1918 in Northeastern Thailand. Unpublished Bachelor's Degree Science Project. Department Faculty of Science, Mahasakham University, Maha Sarakham. [In Thai with English abstract.]

Zilch A. 1966. Die Typen und Typoide des Natur-Museums Senckenberg, 35: Mollusca, Camaenidae (5). Archiv für Molluskenkunde 95: 293-319.

Manuscript received: 6 February 2020

Manuscript accepted: 24 August 2021

Published on: 17 September 2021

Topic editor: Rudy Jocqué

Section editor: Thierry Backeljau

Desk editor: Pepe Fernández 
Printed versions of all papers are also deposited in the libraries of the institutes that are members of the EJT consortium: Muséum national d'histoire naturelle, Paris, France; Meise Botanic Garden, Belgium; Royal Museum for Central Africa, Tervuren, Belgium; Royal Belgian Institute of Natural Sciences, Brussels, Belgium; Natural History Museum of Denmark, Copenhagen, Denmark; Naturalis Biodiversity Center, Leiden, the Netherlands; Museo Nacional de Ciencias Naturales-CSIC, Madrid, Spain; Real Jardín Botánico de Madrid CSIC, Spain; Zoological Research Museum Alexander Koenig, Bonn, Germany; National Museum, Prague, Czech Republic. 